\title{
Family History of Hypertension: Impact on Blood Pressure, Anthropometric Measurements and Physical Activity Level in Schoolchildren
}

Tatiana Affornali Tozo, ${ }^{1,2}{ }^{\circledR}$ Beatriz Oliveira Pereira, ${ }^{\circledR}$ Francisco José de Menezes Junior, ${ }^{2}{ }^{\circledR}$ Cristianne Morgado Montenegro, $^{1 \oplus}$ Carla Marisa Maia Moreira, ${ }^{3 \oplus}$ Neiva Leite $^{2}{ }^{\circledR}$

Universidade do Minho, ${ }^{1}$ Instituto de Educação, Braga - Portugal

Universidade Federal do Paraná, ${ }^{2}$ Departamento de Educação Física, Curitiba, PR-Brazil

Universidade do Porto, ${ }^{3}$ Porto - Portugal

\section{Abstract}

Background: A family history of arterial hypertension (AH), combined with environmental risk factors, is directly related to the development of $\mathrm{AH}$.

Objective: To evaluate the frequency of $\mathrm{AH}$, anthropometric indicators and level of physical activity and their association with a family history (FH) of AH in school children.

Methods: Cross-sectional study with 118 students, aged between 11 and 17 years, of both sexes. Waist circumference (WC), weight, height, level of physical activity and FH of HA were collected. Body mass index z score (BMI-z) and waist-to-height ratio (WHtR) were calculated. Binary logistic regression model was used to verify the chance risk, with significance $\mathrm{p}<0.05$.

Results: Of the 118 parents who answered the questionnaire, 34.7\% had a positive FH of AH. Girls with a positive FH had higher means of WC ( $p=0,004)$, BMI $(\mathrm{p}=0,020)$, and systolic blood pressure (SBP) $(\mathrm{p}=0,006)$ than boys, and a higher risk of being overweight (OR=4,48; 95\%CI:1,55-12,94), and having elevated WHtR (OR=5.98; 95\%CI:1.6621.47) and SBP (OR=3,07; 95\%CI:1,03-9,13) than girls without a $\mathrm{FH}$, but they practice more vigorours moderate physical activity (MVPA) $(\mathrm{p}=0,039)$. On the other hand, no differences in these parameters were observed between boys with and without a FM of AH.

Conclusions: Overweight and a FH of hypertension were associated with an increased risk for AH in girls. This was not observed among boys, perhaps due to more active lifestyle.

Keywords: Heredity/genetics; Hypertension/genetics; Blood Pressure; Anthropometry; Physical Activity; Obesity; Schoolchildren.

\section{Introduction}

The prevalence of arterial hypertension $(\mathrm{AH})$ has increased worldwide, and considering that it has a multifactorial cause and a low control rate, it has been regarded as a public health problem. ${ }^{1}$ The appearance of AH depends on the interaction of environmental and genetic factors. ${ }^{2}$ In this respect, predictive risk models can be used to identify those with higher and lower probability of developing early $\mathrm{AH}$ and are essential for the prevention of complications in adult life. ${ }^{3,4}$

Primary prevention has been recommended for individuals with a family history of $\mathrm{AH}$, and consequently, with an increased risk of developing AH. Children of hypertensive parents, compared with children of normotensive parents, tend to have higher blood pressure to levels compatible with prehypertension. ${ }^{5}$ For this reason, individuals should be screened for

Mailing Address: Tatiana Affornali Tozo

Paulino Siqueira Cortes, 1986. Postal Code: 83005-030, Siqueira da Motta., São José dos Pinhais - PR, Brazil.

E-mail: tatinali@yahoo.com.br 
family history of $\mathrm{AH}$, since children of hypertensive parents (both mother and father) have higher odds of becoming hypertensive as compared with children of one hypertensive parent. ${ }^{6,7}$

The influence of lifestyle on the health of different populations has been extensively discussed and indicated that risk behaviors in adolescence can lead to numerous diseases, including hypertension. ${ }^{8,9}$ An environmental aspect, related to HA in this age group, that has reached major proportions is sedentary lifestyle which, combined with a high-calory diet, may result in obesity, metabolic disorders, and low cardiorespiratory fitness, which are contributing factors to cardiovascular disease. ${ }^{10,11}$

Therefore, the importance of an early identification of an increased risk for hypertension has been highlighted by several studies in which anthropometric assessments were performed. ${ }^{12,13}$ However, these studies did not assess the impact of a family history of $\mathrm{AH}$ on blood pressure levels, which would involve the assessment of both genetic and environmental factors.

The assessment of physical activity levels through reliable procedures and instruments can be essential for the surveillance and evaluation of the effectiveness of intervention actions aimed at protective effects on blood pressure levels. ${ }^{14}$ Therefore, the aim of the present study was to identify blood pressure levels and the prevalence of $\mathrm{AH}$ associated with family history, and their relationship with anthropometric indicators of obesity and physical activity level in schoolchildren.

\section{Methods}

This is a cross-sectional study with a sample of 118 students (11 to 17 years old), selected by convenience, from private elementary and high schools in the city of São José do Pinhais, Paraná, in southern Brazil. After the consent of the educational institutions, visits were made to the classrooms for presentation of the research objectives to the students and invitation for participation. Data collection was performed by trained employees, under responsibility of one of the investigators.

The proportional stratified sampling procedure was used, so that schools with a larger population contributed more to the sample. The study excluded pregnant girls, individuals with limitations that prevented them from participating in a procedure, and those who did not sign the informed consent form. This study was approved by the Research Ethics Committee of the Pontifícia Universidade Católica do Paraná, PUC - PR (approval number 2198319). Sample power was calculated afterwards using the GPower v3.1 program. The t-test statistic was used for analysis of the presence of the family history of hypertension. An effect size of 0.50 was assigned $(\alpha 0.05)$. Based on these parameters and the final sample size (118 schoolchildren), we observed a sample power of 0.82 in the study.

Age at peak height velocity (PHV) was used as an indicator of somatic maturity. ${ }^{15}$ Anthropometric measurements were collected at school, following the procedures recommended by the Anthropometric Standardization Reference Manual. ${ }^{16}$ Body mass (BM) [kg] was evaluated using a Seca Aura 807 digital flat platform scale, with $100 \mathrm{~g}$ accuracy and capacity of $150 \mathrm{~kg}$, with the participant wearing light clothing, standing barefoot, feet together on the center of the platform. For height measurement students were instructed to stand barefoot with their feet together, arms along their body, and head positioned in the Frankfurt Plane (looking forward), with their heels, buttocks and shoulders were in contact with the vertical backboard of a portable stadiometer (AVANUTRI).

The body mass index (BMI) was calculated for evaluation of nutritional status, by dividing body mass $(\mathrm{kg})$ by the square of height $\left(\mathrm{m}^{2}\right)$. In addition, the BMI z-score (BMI-z) was calculated according to the Growth reference data for 5 -19 years ${ }^{17}$ using the WHO Anthro Plus ${ }^{\circledR}$ software, version 1.0.4. Participants with BMI-z between $\geq-2$ and $<+1$ were classified as overweight, between $\geq 1$ and $<2$ as obese, and those with BMI-z $\geq+2$ according to age group and gender were classified as normal weight.

Waist circumference (WC) was measured using a flexible and inelastic measuring tape at the nearest $0.1 \mathrm{~cm}$, at the midpoint between the last costal arch and the iliac crest. The classification of WC was made following the cut- offs proposed by Fernández et. al. (2004): ${ }^{18}$ WC values $\leq$ p10: low WC, WC values $\geq$ p10 and < p75: adequate WC, WC values $\geq 75$ and < p90: high WC, and WC values $\geq$ p90: very high WC. Central obesity was defined as WC > p75 for age and sex. The waist-to-height ratio (WHtR) was calculated as waist circumference $(\mathrm{cm}) /$ height $(\mathrm{cm})$ and classified according to the reference values for age and gender. ${ }^{19}$

Blood pressure (BP) was classified according the percentiles for age, sex and height proposed by the 7th Brazilian Guidelines on Arterial Hypertension ${ }^{3}$ and the Fourth Report on the Diagnosis, Evaluation, and Treatment of High Blood Pressure in Children and Adolescents for 
schoolchildren aged from 1 to 17 years old, of both sexes. ${ }^{20}$ Blood pressure was measured by nurses that voluntarily participated in the investigation, in an isolated classroom, in a silent environment. The student was asked not to speak during the measurement, to rest for at least five minutes in a calm environment, not to exercise 60 to 90 minutes before the measurement, not to drink alcoholic beverages, coffee, or food and not to smoke on the same day. At the time of measurement, the students kept their legs uncrossed, feet flat on the floor, back against the chair and relaxed. BP measurements were taken from the right arm, with the palm facing upwards and the elbow slightly flexed; ${ }^{3}$ the cuff was placed at the level of the heart.

Thus, the students were classified based on BP measurements as normotensive individuals: systolic blood pressure (SBP) and/or diastolic blood pressure (DBP) below the 90th percentile; borderline (or prehypertension): percentile between 90 and 95; and hypertensive: percentile equal to or greater than 95 . When BP values were equal to or greater than 120/80 $\mathrm{mmHg}$, even if less than the 90th percentile, the student was considered to be hypertensive. ${ }^{3}$

The family history of $\mathrm{AH}$ was obtained through a questionnaire sent to the adolescents' parents or guardians to identify whether the biological father and biological mother were hypertensive. Participants were then classified into two categories: with "positive family history" (PFH) and "negative family history" (NFH) of hypertension.

The level of physical activity was assessed according to the World Health Organization, which recommends that schoolchildren aged 5 to 17 years should perform a minimum of 60 minutes of moderate-vigorous physical activities daily, ${ }^{21}$ with a weekly volume of 420 minutes of moderate to vigorous activities.

\section{Statistical analysis}

Statistical analysis was performed using the software Statistical Package for the Social Sciences, version 24. Continuous variables were presented as mean \pm standard deviation or median (range interquartile range), while categorical variables were presented as frequency and percentage. The interquartile range was calculated by subtracting quartile $3(75 \%)$ from quartile $1(25 \%)$. Analyses of categorical variables were performed using the chi-square test. Normality of continuous variables was tested using the Shapiro- Wilk test. The unpaired Student's t-test was used for parametric variables, and the Mann-Whitney test for non-parametric variables.
Odds ratio analysis of $\mathrm{PFH}$ and NFH was performed for the anthropometric variables and (MVPA) through binary logistic regression, adjusted for PHV. A significance level of $\mathrm{p}<0.05$ was considered for all analyses.

\section{Results}

A total of 336 volunteer schoolchildren of both sexes, aged 11 to 17 years old (mean age $14.6 \pm 1.6$ years), 173 girls (mean age $14.7 \pm 1.6$ ) and 163 boys (mean age 14.4 \pm 1.6 ) were selected by convenience. After applying the questionnaire on the family history of $\mathrm{AH}, 118$ students (mean age $14.6 \pm 1.5$ years) remained in the study, 75 girls (mean age $14.9 \pm 1.4$ years) and 43 boys (mean age $14.1 \pm 1.5)$.

Table 1 presents the general characteristics of the sample according to family history (PFH or NFH). Girls with $\mathrm{PFH}$ of $\mathrm{AH}$ had lower PHV, higher weight, height, WC, BMI, BMI-z, SBP and physical activity level than girls with NFH.

Table 2 presents the proportion of individuals with PFH and NFH by sex. Greater proportions of girls with central obesity, overweight, high WHtR and prehypertension were observed among those with PFH than NHF. These differences were not observed among boys.

Table 3 shows the distribution of individuals by anthropometric variables, $\mathrm{BP}$, and physical activity level by sex and family history of AH. There was a higher frequency of hypertension in individuals with central obesity, overweight and high WHtR than those with adequate values. Likewise, hypertensive subjects with central obesity, overweight and high WHtR had higher frequency of elevated SBP, but not DBP.

According to the risk analysis (Table 4), it was found that for the total sample, individuals with a $\mathrm{PFH}$ of $\mathrm{AH}$ were 2.24 times more likely to be overweight and 2.57 times more likely to have increased WHtR. Girls with PFH had a 4.48-fold higher risk of being overweight, 5.98-fold higher risk of having increased WHtR, and 3.07-fold higher risk of being hypertensive.

\section{Discussion}

The present study evaluated the association between the diagnosis of hypertension in schoolchildren and the presence of hypertension in their parents. It was observed that one third of the participants had a PFH of $\mathrm{AH}$; girls with a PFH of hypertension were more likely to be overweight, centrally obese, and have increased 


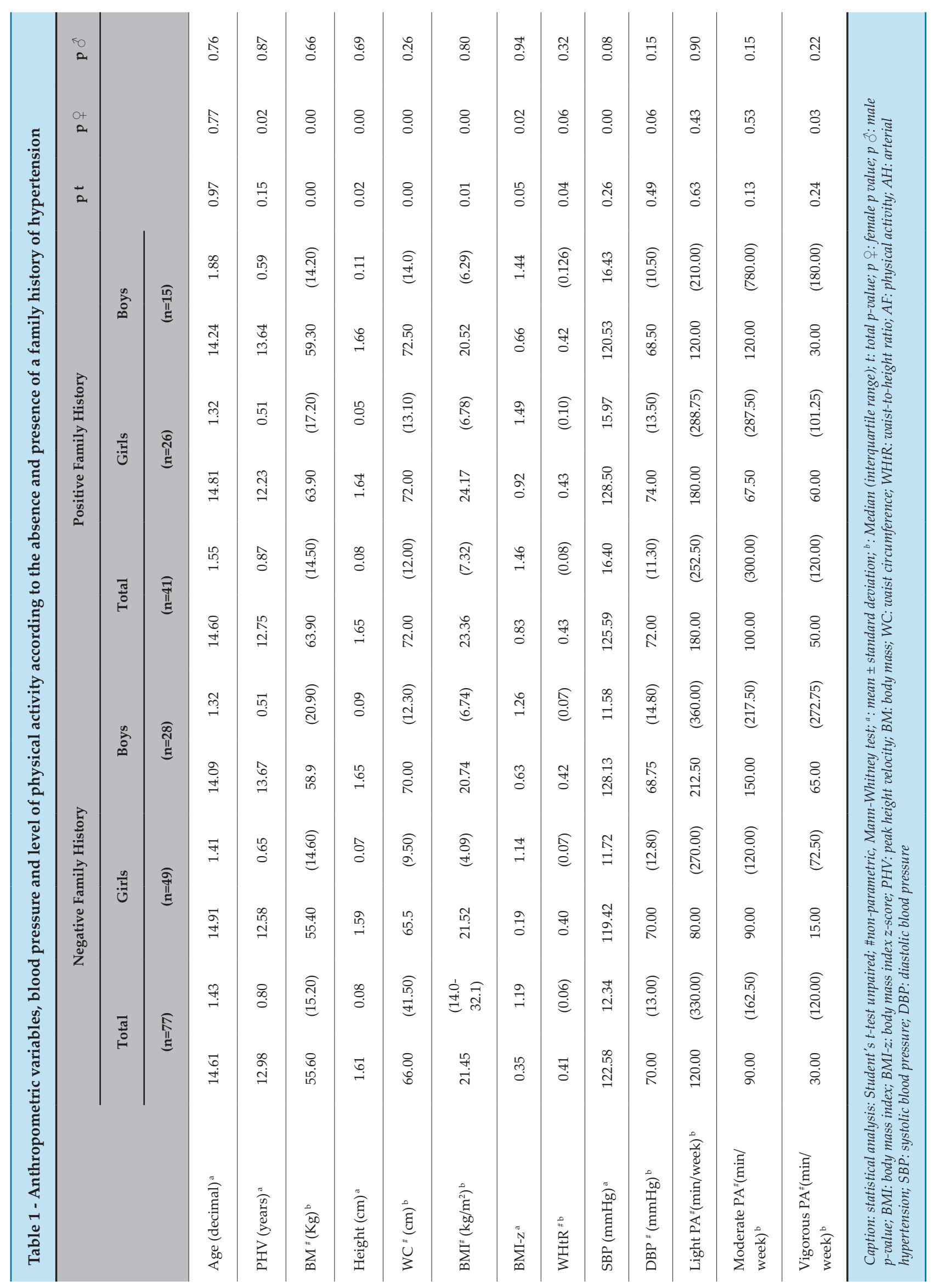




\begin{tabular}{|c|c|c|c|c|c|c|c|c|c|c|c|}
\hline & & \multicolumn{4}{|c|}{ Girls } & \multicolumn{6}{|c|}{ Boys } \\
\hline & & \multicolumn{2}{|c|}{ PFH $(n=26)$} & \multicolumn{2}{|c|}{ NFH $(n=49)$} & \multicolumn{3}{|c|}{ PFH (n=15) } & \multicolumn{2}{|c|}{ NFH $(n=28)$} & \multirow[b]{2}{*}{$\mathbf{p}$ ठ } \\
\hline & & F & $\%$ & $\mathbf{F}$ & $\%$ & $\mathbf{p}$ ㅇ & $\mathbf{F}$ & $\%$ & $\mathbf{F}$ & $\%$ & \\
\hline \multirow{2}{*}{ WC (\%) } & Normal & 21 & $81 \%$ & 47 & $96 \%$ & \multirow{2}{*}{0,03} & 11 & $73 \%$ & 23 & $82 \%$ & \multirow{2}{*}{$0.4 \mathrm{C}$} \\
\hline & Central obesity & 5 & $19 \%$ & 2 & $4 \%$ & & 4 & $27 \%$ & 5 & $18 \%$ & \\
\hline \multirow{2}{*}{ BMI-z (\%) } & Normal weight & 11 & $42 \%$ & 37 & $76 \%$ & \multirow{2}{*}{0,00} & 10 & $67 \%$ & 16 & $57 \%$ & \multirow{2}{*}{0.5} \\
\hline & Overweight & 15 & $58 \%$ & 12 & $24 \%$ & & 5 & $33 \%$ & 12 & $43 \%$ & \\
\hline \multirow{2}{*}{ WHtR (\%) } & Adequate & 16 & $62 \%$ & 44 & $90 \%$ & \multirow{2}{*}{0,00} & 11 & $73 \%$ & 20 & $71 \%$ & \multirow{2}{*}{$0.8 \mathrm{~s}$} \\
\hline & High & 10 & $38 \%$ & 5 & $10 \%$ & & 4 & $27 \%$ & 8 & $29 \%$ & \\
\hline \multirow{2}{*}{ MVPA (WHO) } & Active & 7 & $27 \%$ & 5 & $10 \%$ & \multirow{2}{*}{0,11} & 5 & $33 \%$ & 9 & $32 \%$ & \multirow{2}{*}{0.93} \\
\hline & Inactive & 19 & $73 \%$ & 43 & $90 \%$ & & 10 & $67 \%$ & 19 & $68 \%$ & \\
\hline \multirow{3}{*}{$\mathrm{BP}(\%)$} & Normal & 8 & $31 \%$ & 30 & $61 \%$ & \multirow{3}{*}{0,03} & 7 & $47 \%$ & 7 & $25 \%$ & \multirow{3}{*}{0.10} \\
\hline & Pre-hypertensive & 4 & $15 \%$ & 3 & $6 \%$ & & 5 & $33 \%$ & 6 & $21 \%$ & \\
\hline & Hypertensive & 14 & $54 \%$ & 16 & $33 \%$ & & 3 & $20 \%$ & 15 & $54 \%$ & \\
\hline \multirow{3}{*}{ SBP $(\%)$} & Normal & 9 & $35 \%$ & 31 & $63 \%$ & \multirow{3}{*}{0,06} & 7 & $47 \%$ & 9 & $32 \%$ & \multirow{3}{*}{0.15} \\
\hline & Pre-hypertensive & 3 & $12 \%$ & 3 & $6 \%$ & & 5 & $33 \%$ & 5 & $18 \%$ & \\
\hline & Hypertensive & 14 & $54 \%$ & 15 & $31 \%$ & & 3 & $20 \%$ & 14 & $50 \%$ & \\
\hline \multirow{3}{*}{ DBP (\%) } & Normal & 18 & $69 \%$ & 41 & $84 \%$ & \multirow{3}{*}{0,16} & 14 & $93 \%$ & 21 & $75 \%$ & \multirow{3}{*}{0.25} \\
\hline & Pre-hypertensive & 3 & $12 \%$ & 1 & $2 \%$ & & 1 & $7 \%$ & 3 & $11 \%$ & \\
\hline & Hypertensive & 5 & $19 \%$ & 7 & $14 \%$ & & 0 & $0 \%$ & 4 & $14 \%$ & \\
\hline
\end{tabular}

Caption: statistical analysis: chi-square; ㅇ: female; ภ̊: male; F: frequency; PHF: positive family history; NHF: negative family history; BMIz: body mass index z-score; WC: waist circumference; WHtR: waist-to-height ratio; MVPA: moderate-to-vigorous physical activity; WHO: World Health Organization; BP: blood pressure; SBP: systolic blood pressure; DBP: diastolic blood pressure

SBP values than girls with NFH. However, there was no increased risk of $\mathrm{AH}$ and high anthropometric indicators in boys with a PFH of $\mathrm{AH}$.

In the present investigation, higher means of SBP were identified among girls with a PFH, which suggests an influence of genetic factors upon these alterations, as found in some studies. ${ }^{22}$ However, studies suggest that genetic factors are responsible for about $30 \%$ change in blood pressure, that is, AH may be much more frequent in subjects with one hypertensive parent. ${ }^{23}$ Indeed, many studies have reported an important association between the presence of high BP and family history of hypertension, and highlighted the need for research to detect the likelihood of their children developing chronic diseases. ${ }^{24,25}$
Several lines of evidence indicate that both genetic and environmental factors are involved in BP elevation in schoolchildren. ${ }^{26}$ In the present study, although the prevalence of hypertension was not different between children with $\mathrm{PFH}$ and $\mathrm{NFH}$ of $\mathrm{AH}$, those with altered anthropometric measurements of obesity (BMI, WC and WHtR) were more likely to be hypertensive-approximately one third of hypertensive students had high WC and WHtR, while more than half were classified as overweight. This association between obesity anthropometric data and blood pressure elevation was previously reported, ${ }^{27}$ underscoring the impact of excess weight and abdominal fat on the etiology of hypertension. According to Tozo et al., ${ }^{14}$ students with high WC and overweight (according to BMI) children may have, respectively, 6.11 times and 2.91 times higher 


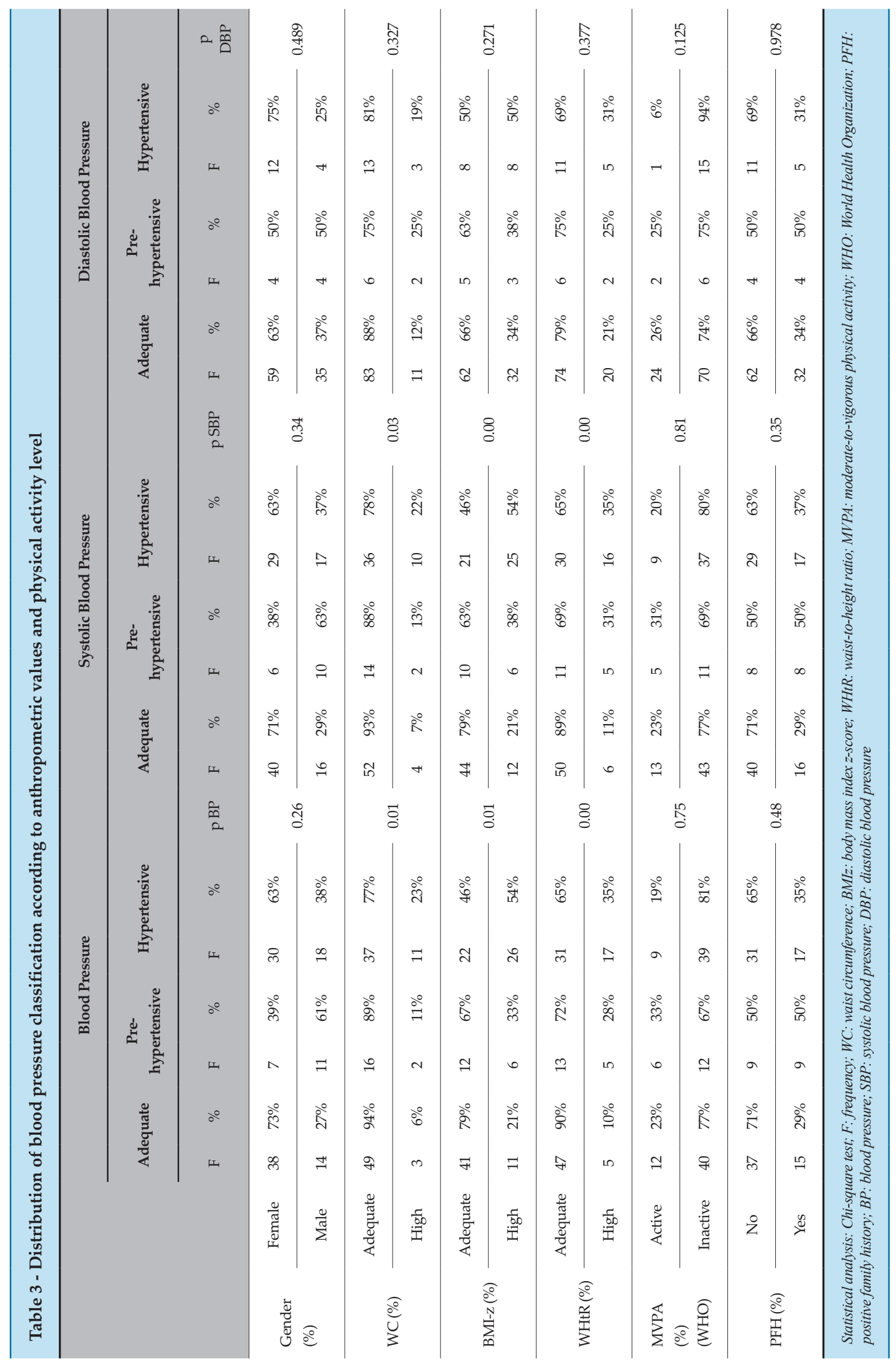


Table 4 - Odds ratios of the presence of family history of hypertension for anthropometric variables. Physical activity level and arterial hypertension

\begin{tabular}{|c|c|c|c|c|c|c|}
\hline & $\begin{array}{c}\text { PFH - Total } \\
n=118\end{array}$ & $\mathrm{p}$ & $\begin{array}{c}\text { PFH - Girls } \\
\text { n=75 }\end{array}$ & \multirow{2}{*}{$\mathrm{p}$} & $\begin{array}{c}\text { PHF - Boys } \\
n=43\end{array}$ & \multirow{2}{*}{$\mathrm{p}$} \\
\hline & OR $(95 \% C I)$ & & OR $(95 \% C I)$ & & OR $(95 \% C I)$ & \\
\hline Overweight (BMI-z) & $2.24(1.02-4.89)$ & 0.04 & $4.48(1.55-12.94)$ & 0.01 & $0.67(0.18-2.46)$ & 0.54 \\
\hline Central obesity (WC) & $2.81(0.96-8.22)$ & 0.06 & $4.34(0.74-25.21)$ & 0.10 & $1.66(0.36-7.56)$ & 0.51 \\
\hline Elevated WHtR & $2.57(1.06-6.15)$ & 0.04 & $5.98(1.66-21.47)$ & 0.01 & $0.91(0.27-3.77)$ & 0.91 \\
\hline $\begin{array}{l}\text { Physically active } \\
\text { (MVPA-WHO) }\end{array}$ & $0.57(0.23-1.40)$ & 0.23 & $0.38(0.11-1.34)$ & 0.13 & $0.98(0.22-4.25)$ & 0.99 \\
\hline Pre-hypertensive (BP) & $2.62(0.83-8.20)$ & 0.10 & $4.43(0.77-2.35)$ & 0.09 & $0.83(0.16-4.16)$ & 0.83 \\
\hline Hypertensive (BP) & $1.37(0.59-3.22)$ & 0.46 & 3.07 (1.03 - 9.13) & 0.04 & $0.20(0.03-1.02)$ & 0.05 \\
\hline
\end{tabular}

risk of being hypertensive. This last result was similar to the study by Moser et al., ${ }^{11}$ which BMI (odds ratio of 2.9) and triceps skinfold (odds ratio of 1.9) were predictors of high $\mathrm{BP}$, regardless of abdominal adiposity, sexual maturation and socioeconomic level.

Thus, our results reinforce that both genetic and anthropometric factors are important predictors of $\mathrm{AH}$ in schoolchildren. Several reports with adolescents and adults have shown a relationship between blood pressure and anthropometric information, suggesting obesity as a strong risk factor for the development of hypertension. ${ }^{14,28,29}$ In addition, although WC and WHtR measurements cannot discriminate between visceral fat and subcutaneous fat, there is evidence that individuals with increased WC have a higher risk of hypertension, diabetes, dyslipidemia and metabolic syndrome. ${ }^{30}$

In the present investigation, it was observed that girls with a family history of $\mathrm{AH}$ had higher anthropometric and SBP values, and also practiced more (vigorous) physical activity. This finding may reflect an engagement in physical activities as a strategy to reduce body weight, in addition to a greater concern on the part of parents for their children to maintain an active lifestyle, given the benefits of physical activity for health. Besides, unhealthy behaviors such as physical inactivity, and poor diet quality may increase the risk of hypertension. In this sense, the practice of physical activity can contribute to the reduction of BP levels, metabolic risk and obesity. ${ }^{31,32}$
Our results indicate that about a quarter of hypertensive students met the recommendations for moderate-tovigorous physical activity and did not have a history of hypertension. In fact, previous studies failed to show a direct relationship between $\mathrm{AH}$ and the practice of moderate-intensity physical activity. ${ }^{14,33}$ However, physical activity is known to be an important tool in the prevention and treatment of obesity, ${ }^{30}$ and may hence act as an adjunct in the prevention and treatment of hypertension.

In this study, it was observed that in boys, the risk of $\mathrm{AH}$ was not different between those with and without a $\mathrm{PFH}$ of $\mathrm{AH}$. In this sense, interventions towards an increase in physical activity level could positively contribute with BP levels in this population. ${ }^{32}$ Furthermore, the results of this research show that boys practice more physical activity than girls, reinforcing the protective aspect of this practice, which was also demonstrated in other studies. ${ }^{34}$ In parallel, studies have pointed out that the lack of public safety, together with the globalized and computerized world, contribute to a sedentary behavior. ${ }^{8,35}$ Therefore, low level of moderate to vigorous physical activity, in and out of school, in the juvenile population supports the idea that a sedentary child may be more likely to become an adult with possible problems. of health. . $^{36,37}$

The present work has some limitations that must be considered when interpreting the results. First, the crosssectional nature of the study precludes the establishment 
of cause-effect relationships. A parental diagnosis of $\mathrm{AH}$ was self-reported, which can be considered a limiting factor. In addition, the assessment of variables of socioeconomic status and dietary salt intake was not performed. However, this study was able to assess BP levels and the frequency of $\mathrm{AH}$ associated with family history of $\mathrm{AH}$ in children, establish the relationship of $\mathrm{BP}$ with anthropometric indicators of obesity, in addition to highlight the importance of the practice of moderate-tovigorous physical acidity as a protective factor against changes in BP in schoolchildren.

\section{Conclusion}

We conclude that the diagnosis of hypertension in school in the study is associated with excess weight and abdominal fat accumulation. In addition, in girls with a PFH of $\mathrm{AH}$, elevated BP was associated with excess weight. No significant relationship was found between the presence of $\mathrm{AH}$ and a PFH among boys, but the higher percentage of physically active individuals (compared with girls) supports the protective role of physical activity in maintaining adequate BP values.

This study highlighted the need for overweight and obesity prevention in during childhood and adolescence, and the importance of behavioral and lifestyle changes, including physical activity, periodic anthropometric and BP assessment, as well as a greater participation of parents for the prevention of chronic non-communicable diseases.

\section{Author contributions}

Conception and design of the research: Tozo TA, Pereira BO, Montenegro CM, Moreira CMM, Leite N. Acquisition of data: Tozo TA. Analysis and interpretation of the data: Tozo TA, Pereira BO, Menezes Junior FJ, Montenegro CM, Moreira CMM, Leite N. Statistical

\section{References}

1. Bloch KV, Klein CH, Szklo M, Kuschnir MCC, De Azevedo Abreu G Barufaldi LA, et al. ERICA: Prevalences of hypertension and obesity in Brazilian adolescents. Rev Saude Publica. 2016;50(suppl 1):1-12.

2. Miura T, Saitoh S, Akasaka H, Mitsumata K, Ohnishi H. Effects of Parental Hypertension on Longitudinal Trends in Blood Pressure and Plasma Metabolic Profile. Hypertension. 2012;60(5):1124-30.

3. Malachias M, Souza W, Plavnik FL, Rodrigues C, Brandão A. 7a Diretriz Brasileira De Hipertensão Arterial. Arq Bras Cardiol. 2016;107(3):14-7 analysis: Menezes Junior FJ. Obtaining financing: Pereira BO, Leite N. Writing of the manuscript: Tozo TA, Pereira BO, Menezes Junior FJ, Montenegro CM, Moreira CMM, Leite N. Critical revision of the manuscript for intellectual content: Tozo TA, Pereira BO, Moreira CMM, Leite N.

\section{Potential Conflict of Interest}

No potential conflict of interest relevant to this article was reported.

\section{Sources of Funding}

This study was funded by Coordination for the Improvement of Higher Education Personnel (CAPES), the National Council for Scientific and Technological Development (CNPq), supported by Portuguese national funds through the FCT (Foundation for Science and Technology) within the framework of the CIEC (Research Center for Child Studies of the University of Minho) project under the reference UIDB/00317/2020.

\section{Study Association}

This article is part of the doctoral thesis by Tatiana Affornali Tozo - University of Minhounder co guardianship regime with Universidade Federal do Paraná.

\section{Ethics approval and consent to participate}

This study was approved by the Ethics Committee of the Pontifical Catholic University of Paraná, PUC - PR under the protocol number CAAE71324017.1.0000.0020/2017. All the procedures in this study were in accordance with the 1975 Helsinki Declaration, updated in 2013. Informed consent was obtained from all participants included in the study.

4. Flynn JT. High blood pressure in the young: why should we care? Acta Paediatr Int J Paediatr. 2018;107(1):14-9.

5. Krieger EM, Lopes HF, Bortolloto LA, Consolin-Colombo FM, Giorgi D marcelo A, Lima JJG de, et al. Hipertensão arterial: bases fisiopatológicas e prática clínica. 1o edição. São Paulo; 2013.

6. Gupta-Malhotra M, Hashmi SS, Barratt MS, Milewicz DM, Shete S. Familial aggregation of first degree relatives of children with essential hypertension. Blood Press. 2018;27(5):289-96. 
7. Collier SR, Landram MJ, Landram M, Street R. VHRM-29138-thetreatment-of-prehypertension--lifestyle-and-or-medicatio. Vasc Health Risk Manag. 2012;2012:613-9.

8. Costa C dos S, Flores TR, Wendt A, Neves RG, Assunção MCF, Santos IS. Comportamento sedentário e consumo de alimentos ultraprocessados entre adolescentes brasileiros: Pesquisa Nacional de Saúde do Escolar (PeNSE), 2015. Cad Saude Publica. 2018;34(3):1-12.

9. Ferreira RW, Rombaldi AJ, Ricardo LIC, Hallal PC, Azevedo MR. Prevalência de comportamento sedentário de escolares e fatores associados. Rev Paul Pediatr. 2016;34(1):56-63.

10. Leite N, Milano GE, Cieslak F, Stefanello JMF, Radominski RB. Aptidão cardiorrespiratória, perfil lipídico e metabólico em adolescentes obesos e não-obesos. Rev Bras Educ Física e Esporte. 2009;23(3):275-82.

11. Moser DC, Giuliano I de CB, Titski ACK, Gaya AR, Coelho-e-Silva MJ, Leite N. Anthropometric measures and blood pressure in school children. J Pediatr. 2013;89(3):243-9.

12. Lo K, Wong $\mathrm{M}$, Khalechelvam $\mathrm{P}$, Tam $\mathrm{W}$. Waist-to-height ratio, body mass index and waist circumference for screening paediatric cardio-metabolic risk factors: a meta-analysis. Obes Rev. 2016;17(12):1258-75.

13. Pazin DC, Rosaneli CF, Olandoski M, Oliveira ERN de, Baena CP, Figueredo AS, et al. Waist Circumference is Associated with Blood Pressure in Children with Normal Body Mass Index: A Cross-Sectional Analysis of 3,417 School Children. Arq Bras Cardiol. 2017;6:509-15.

14. Tozo TA, Pereira BO, Junior FJ de M, Montenegro CM, Moreira CMM, Leite N. Medidas Hipertensivas em Escolares : Risco da Obesidade Central e Efeito Protetor da Atividade Física Moderada-Vigorosa. Arq Bras Cardiol. 2020;115(1)1-8.

15. Moore SA, McKay HA, Macdonald H, Nettlefold L, Baxter-Jones ADG, Cameron N, et al. Enhancing a somatic maturity prediction model. Med Sci Sports Exerc. 2015;47(8):1755-64.

16. Lohman TG, Roche AF, Martorell R. Anthropometric standardization reference manual. Champaign:Human Kinetics Books. 1988. 177 p.

17. Onis M de, Onyango AW, Borghi E, Siyam A, Nishidaa C, Siekmanna J. Development of a WHO growth reference for school-aged children and adolescents. Bull World Health Organ. 2007;85 (9):660-7.

18. Fernández JR, Redden DT, Pietrobelli A, Allison DB. Waist circumference percentiles in nationally representative samples of African-American, European-American, and Mexican-American children and adolescents. J Pediatr. 2004;145(4):439-44.

19. Nambiar S, Hughes I, Davies PS. Developing waist-to-height ratio cutoffs to define overweight and obesity in children and adolescents. Public Health Nutr. 2010;13(10):1566-74.

20. The Fourth report on the diagnosis, evaluation and treatment of high blood pressure in children and adolescent. National High Blood Pressure Education Program Working Group on High Blood Pressure in Children and Adolescents. Pediatrics. 2004;114(2 Suppl 4th Report):55-76.

21. World Health Organization. (WHO). Global Recommendations on Physical Activity for Health . Geneva; 2010.

22. Mendes MJF de L, Alves JGB, Alves AV, Siqueira PP, Freire EF de C. Associação de fatores de risco para doenças cardiovasculares em adolescentes e seus pais. Rev Bras Saúde Matern Infant. 2006;6(Suppl 1):49-54.

23. Gupta-Malhotra M, Banker A, Shete S, Hashmi SS, Tyson JE, Barratt MS, et al. Essential hypertension vs. secondary hypertension among children. Am J Hypertens. 2015;28(1):73-80.

24. Oikonen M, Würtz P, Raitakari OT, Seppälä I, Laitinen T, Mikkilä V, et al. Childhood Physical, Environmental, and Genetic Predictors of Adult Hypertension. Circulation. 2012;126(4):402-9.

25. Wang N-Y, Young JH, Meoni LA, Ford DE, Erlinger TP, Klag MJ. Blood pressure change and risk of hypertension associated with parental hypertension: The Johns Hopkins precursors study. Arch Intern Med. 2008;168(6):643-8.

26. Mariath $A B$, Grillo LP. Influência do estado nutricional , circunferência da cintura e história familiar de hipertensão sobre a pressão arterial de adolescentes. Rev Ciência Médica. 2008;17(2):65-74.

27. Manios Y, Karatzi K, Protogerou AD, Moschonis G, Tsirimiagou C, Androutsos $\mathrm{O}$, et al. Prevalence of childhood hypertension and hypertension phenotypes by weight status and waist circumference: the Healthy Growth Study. Eur J Nutr. 2018;57(3):1147-55.

28. Moser DC, De Carlos Back Giuliano I, Titski ACK, Gaya AR, Coelho-eSilva MJ, Leite N. Anthropometric measures and blood pressure in school children. J Pediatr. 2013;89(3):243-9.

29. Köchli S, Endes K, Steiner R, Engler L, Infanger D, Schmidt-Trucksäss A, et al. Obesity, High Blood Pressure, and Physical Activity Determine Vascular Phenotype in Young Children. Hypertension. 2019;73(1):153-61.

30. Leite N, Moser DC, Góes SM, Góes SM, Cieslak F, Eisfeld Milano G, et al Medidas Hipertensivas e excesso de peso em escolares da rede pública de Curitiba - PR. Fisioter em Mov. 2009;22(4):477-87.

31. Santana F da S, Palmeira AC, Santos MAM dos, Farah BQ, Souza BCC de, Ritti Dias RM. Association between active commuting and elevated blood pressure in adolescents. Einstein. 2017;15(4):415-20.

32. Tarp J, Child A, White T, Westgate K, Bugge A, Grøntved A, et al. Physical activity intensity, bout-duration, and cardiometabolic risk markers in children and adolescents. Int J Obes. 2018;42(9):1639-50.

33 Sadoh WE, Sadoh AE, Onyiriuka AN. Physical activity, body mass index and blood pressure in primary school pupils attending private schools. Afr Health Sci. 2016;16(4):947-53.

34. Agostinis-Sobrinho C, Ruiz JR, Moreira C, Lopes L, Ramírez-Vélez R, García-Hermoso A, et al. Changes in muscular fitness and its association with blood pressure in adolescents. Eur J Pediatr. 2018;177(7):1101-9.

35. Lourenço CLM, Zanetti HR, Amorim PR dos S, Mota JAPS, Mendes EL. Comportamento sedentário em adolescentes: prevalência e fatores associados Sedentary behavior in adolescents: prevalence and associated factors. R Bras Ciência e Mov. 2018;26(2):23-32.

36. Guerra PH, Farias Júnior JC de, Florindo AA. Sedentary behavior in Brazilian children and adolescents: a systematic review. Rev Saude Publica. 2016;50:9

37. Regis MF, Oliveira LMFT de, Santos ARM dos, Leonidio A da CR, Diniz PRB, Freitas CMSM de. Urban versus rural lifestyle in adolescents: associations between environment, physical activity levels and sedentary behavior. Einstein. 2016;14(4):461-7. 